\title{
Polifonia de Vozes: o 'multicultural planning' como método de avaliação de políticas culturais produzidas no espaço urbano
}

\section{Voices' polyphony: the multicultural planning as a method of cultural policies' evaluation produced in the urban space}

\author{
João Luiz Pereira Domingues* \\ joaolpdomingues@gmail.com
}

Resumo

$\mathrm{O}$ artigo se dedica à reflexão em torno da relação entre as políticas culturais, a esfera pública e seus desdobramentos territoriais, tendo como acento a discussão metodológica. $\mathrm{O}$ que o artigo propõe ressaltar é a possibilidade de que certos grupos e indivíduos sejam invisibilizados ou não tematizados pela aparência consensual das políticas culturais. Desta feita, tenta-se aqui traduzir um modelo metodológico de planejamento urbano para fins de diminuição do risco de atrofia de expressões culturais na cidade. Ao tematizar o universo cultural na teoria do planejamento, o Multicultural Planning rejeita a adoção dos modelos de racionalidade instrumental em favor de um modelo de reconhecimento de experiências que ressaltam diferentes leituras sobre a construção da realidade e das diversas possibilidades de organização de práticas coletivas de administração e planejamento urbano e cultural.

Palavras-chave: políticas culturais; insurgência; território.

\section{Abstract:}

The article purposes to reflect on the relation between cultural policies, the public sphere and its territorial developments, with a focus on the metodologic discussion. What the article wishes to emphasize is the possibility of certain groups and individuals becoming invisible or not thematized by the consensual appearance of cultural policies. Therefore, the attempt is to translate a methodologic model of urban planning with the goal of diminishing the atrophy risk of cultural expressions in the city. By foregrounding the cultural universe in the planning theory, Multicultural Planning rejects the adopotion of instrumental racionality models in favor of a recognition model of experience that highlights diferent lecutures about the construction of reality and of the different possibilities of the organization of colective practices of cultural and urban managment and planning.

Keywords: cultural policies; insurgency; territory.

* Doutor em Planejamento Urbano e Regional pela Universidade Federal do Rio de Janeiro/IPPUR. Professor Adjunto I do Curso de Graduação em Produção Cultural e do Programa de Pós-Graduação em Cultura e Territorialidades da Universidade Federal Fluminense. E-mail: joaolpdomingues@gmail.com. 


\section{Apresentação}

O presente artigo se dedica à reflexão em torno da relação entre as políticas culturais e a esfera pública em sua dimensão urbana, tendo como acento a discussão metodológica. De forma geral, o que será apresentado é a dificuldade na avaliação do fenômeno político-cultural e, em especial, a determinação de seus níveis de abstração normativos dentro das condições concretas de sua realização nas cidades. Desta feita, o que o artigo propõe ressaltar é a possibilidade de que grupos e indivíduos sejam invisibilizados ou não plenamente tematizados pela aparência consensual das políticas culturais em ação nas cidades, atrofiando a dimensão da diversidade cultural e restringindo o acesso aos bens sociais mais raros a um conjunto privilegiado de atores.

Defende-se aqui que no caso das políticas culturais cujo lócus preferencial é o "urbano", as avaliações devem procurar conceber a cidade como uma estrutura onde as relações sociais se realizam em permanente interação, sob um movimento histórico de longa duração e constante transformação, marcada pelos conflitos que caracterizam a sociedade moderna em suas mais variadas instâncias. Isto posto, trabalha-se aqui a ideia de que as avaliações sobre políticas culturais devem desenvolver uma agenda que problematize as diferentes formas de apropriação urbana, ou seja, a natureza territorial na determinação das subjetividades políticas, sob um espaço adequado de institucionalidade que concretize as múltiplas formas de cidadania no campo político-cultural. Desta forma, tais avaliações devem efetivar-se sobre as ações que criam ou renovam as condições para a realização da diversidade e da experiência da alteridade na sociabilidade citadina.

Para enfrentar este desafio, percebeu-se que a concepção mais corrente de políticas culturais generalizadas como políticas de governo seria por demais limitadora para a percepção do conjunto de relações culturais presentes na cidade. Preferiu-se, então, trabalhar a concepção de políticas culturais de maneira mais ampliada, reconhecendo a multidimensionalidade de experiências urbanas e a ampla gama de esferas públicas que constroem a cidadania. Este é o caminho escolhido para reivindicar a noção de que políticas culturais são elaboradas considerando as relações de poder embutidas no conjunto de práticas sociais que operam no tecido urbano. A partir dessa definição, optou-se por um recorte metodológico na pesquisa fundado em dupla dimensão das políticas culturais; as cartográfico-institucionais e as ético-identitárias.

Desta forma, este artigo objetiva produzir uma crítica ao caráter naturalizado do conceito de políticas culturais como gestão tecnocrática, tendo a concepção de pluralismo democrático como tese de fundo para a problematização de sua construção na dinâmica urbana. Como tal, esquadrinha-se a possibilidade de efetivação da substância normativa de deliberação racional e da formação da vontade política coletiva nos marcos do que vem sendo trabalhado nos diferentes tipos de entendimento de democracia pluralista (CARRACEDO, 2003; CLOSA, 2010; FRASER, 2002; HONNETH, 2003).

O que une de forma geral estes diferentes tipos de construção da democracia pluralista é a noção dialógica de formação subjetiva da autonomia, da racionalidade e da ação política, e a disposição hierárquica moral que acompanha a materialidade da esfera pública. O que se pretende explicitar é que os vínculos sociais que constroem estas hierarquias podem encontrar nas políticas culturais um amplo risco de diluição de experiências sociais construtoras da diversidade cultural.

Entretanto, estes entendimentos sobre a democracia pluralista estão amparados em certo déficit territorial de análise, pouco ou não problematizados. Minha intenção é apresentar níveis ampliados de interação entre cultura e território para construir modelos metodológicos que concorram contra a diluição de experiências urbanas, ou seja, contra a negação da própria experiência heterogênea da urbanidade.

Em parte, este movimento é complementado pela própria extensão do planejamento urbano em direção à cultura, pela introdução do Multicultural Planning. Ao tematizar o universo cultural na teoria do planejamento urbano, este método rejeita a adoção dos modelos de racionalidade instrumental em favor de um método de reconhecimento de experiências que ressaltam diferentes leituras sobre a construção da realidade e das diversas possibilidades de organização de práticas coletivas de administração e planejamento (SANDERCOK, 1998, p.20). Neste diálogo, acredito que a experiência do Multicultural Planning, baseadas na oralidade e na historiografia insurgente como forma de privilegiar as vozes subalternas na definição das relações de poder constitutivas do espaço urbano, pode apresentar-se como um aparato metodológico que assinala a preferência por iniciativas de ações culturais contestatórias cujo espaço de insurgência demonstre capacidade de gerar propostas alternativas. 


\section{Políticas culturais, espaço, e polifonia de vozes}

Parte destas considerações será aqui trabalhada tendo como ponto de partida a interação dialética entre cultura, diversidade e território, expressa nas influências que as cidades exercem sobre a vida social de homens e mulheres, marcando seu modo de vida distintivo, com seus indivíduos socialmente heterogêneos (WIRTH, 1976, p.96).

É esta heterogeneidade como característica fundamental que as cidades carregam como seu elo genealógico com as noções de diversidade e diferença (SIMMEL, 1976). Por óbvio, esta condição heterogênea demanda a presença no espaço da cidade de indivíduos que carregam consigo traços múltiplos, mas particulares, de interação com o modo de vida urbano, operando diversas bases de associação, crenças e sistemas de significados sobre a materialidade do espaço em que constroem diferentes noções de cotidiano e de futuro comum no âmbito das cidades e em relação às suas instituições.

Em que pese o enfraquecimento dos laços de parentesco e a substituição de contatos primários por secundários descritos pela sociologia urbana (WIRTH, op.cit), a urbanidade como modo de vida distintivo é reivindicada não apenas para ilustrar as complexidades na reprodução da estrutura social, mas igualmente a radicalização das possibilidades de experiências de alteridade. As cidades, portanto, permitem aos sujeitos sociais construírem para si e reivindicarem socialmente valores da igualdade de diferenças, como princípios constitutivos da própria noção de urbe.

Portanto, habilitar níveis de entendimento sobre o caráter específico de construção das políticas culturais na urbanidade requer mapear e qualificar no interior das dinâmicas de densidade constitutivas das cidades as diferentes formas de ação e organização dos muitos sujeitos sociais ativos mutuamente reconhecidos e publicizados como coletivos.

Igualmente necessário problematizar as referências mais detidas sobre o espaço. Portanto, para perceber a amplitude urbana das políticas culturais, preferi refazer o percurso de Harvey acerca das noções de espaço absoluto, espaço relativo e espaço relacional. Além de estabelecer precisões metodológicas, este caminho orienta a noção de que práticas humanas diferenciadas criam e fazem diferentes usos e conceituações sobre o espaço (HARVEY, 2006).

Ao formular sua teoria microeconômica de uso do solo urbano, Harvey (1980) relaciona três conceitoschave, dialeticamente articulados, para análises da construção histórica do espaço-ambiente. Ao faz̧ê-lo, Harvey desconstrói formas simplistas de análise sobre o espaço, situando-o em constante tensão sob a simultaneidade relacional dessas três estruturas metodológicas. Quanto ao espaço absoluto, Harvey chama atenção para uma "existência independente da matéria", como um algo em si mesmo, incidindo sobre as propriedades absolutas e exclusivas do espaço físico. Sob uma ótica de individuação dos fenômenos, cada parcela de terra, pessoas, construções teriam uma existência própria e identificatória.

Como derivação, cada espaço absoluto só é percebido quando se conecta sobre outra dimensão espacial. A dimensão relativa do espaço trata da relação e da conectividade entre espaços exclusivos, na medida em que os objetos espacializados estabelecem conexões comunicacionais, de mútua influência e de acessibilidade.

As formas absolutas e relativas de espacialização, entretanto, não dariam conta de perceber alguns elementos essenciais. Na divisão tripartite do espaço que constrói a matriz espacial harveniana, a função do espaço relacional se realiza como uma categoria capaz de expressar a unidade contraditória entre processos abstratos de construção do espaço e processos concretos de práticas e conflitos sociais imanentes. Desta forma, o espaço como concebido e o espaço como experimentado refletem certo estatuto ontológico na obra do autor, quando os elementos espacializados contêm relações de totalidade, na medida em que são o lugar de uma "série de relações dentro da totalidade” (HARVEY, op.cit, p. 250). O espaço relacional contesta a totalidade física do espaço, abrindo-o às interpretações e às experiências distintas.

A renovação metodológica empreendida na obra de Harvey permite problematizar a operação discursiva sobre a espacialização da diversidade cultural, quando conectados os termos heterogeneidade e densidade. Para que haja uma coerência intrínseca entre a representação da espacialização nas políticas culturais e sua materialização intraurbana, seria necessário aproximar as dimensões absolutas, relativas e relacionais dos territórios-síntese.

Este ponto de partida é essencial para perceber como o monitoramento no campo das políticas culturais enfrenta uma série de desafios à sua operação nas condições específicas urbanas. Sua mais evidente é a caracterização da relação entre território e política que está contida em cada ação efetiva no espaço social 
Artigos

e que determinará qual o grau de abrangência e quais questões centrais as políticas culturais enfrentarão. Para melhor enfrentar a questão, tendo as noções relacionais do espaço como seu princípio gerativo, o primeiro passo a se tomar nas avaliações é interpelar o conceito de políticas culturais, desconstruindo sua pretensa neutralidade, para indicar que as intervenções na esfera cultural ultrapassam as concepções construídas pelas técnicas de gestão.

Quanto à discussão metodológica para uma avaliação de políticas culturais, preferiu-se aqui não atribuir nenhum limite às questões mais pragmáticas que se revelam nas condições de eficácia e eficiência com vistas à concretização da diversidade cultural. Para superar qualquer confronto entre a possibilidade de governança sobre os direitos culturais e o planejamento tecnocrático baseado em uma racionalidade econômico-burocrática, o entendimento prévio é de que estas ferramentas de avaliação são essenciais, mas mostram-se parciais e limitadas para a apreensão da totalidade de fenômenos que se impõem à agenda das políticas culturais. Assim, são necessárias modalidades complementares de análise para desenhar os caminhos e medir o impacto de uma determinada política. Este método se justifica pelo pressuposto que se segue quanto à concepção de identidade cultural, como unidade primária para qualquer confronto entre os diferentes.

Barbalho (2008) destaca que os empecilhos para a definição de um conceito de políticas culturais guardam ainda uma dificuldade maior por não representar um campo epistemológico, mas ações mediadas de intervenção na vida social, podendo ser, assim, estudadas por diferentes campos científicos. Deste modo, o fenômeno "política cultural" apresenta-se em meio a uma disputa prévia, por seu próprio entendimento. Como tal, variará segundo seus agentes emissores, seus meios de conceber o fenômeno cultural e sua concepção da esfera política.

Desta feita, derivam neste artigo duas abordagens distintas, interpenetráveis e não necessariamente concorrentes sobre as políticas culturais. A primeira sinaliza a relação entre os Estados e instituições de fomento à produção, envolvendo as diversas formas de produção da cultura e seus agentes, sugerindo a importância econômica dos bens culturais e, portanto, a possibilidade de sua sistematização em programas públicos ou privados de apoio à produção de bens e à preservação e fruição da memória e do patrimônio (CANCLINI, 2000). Rompendo com qualquer concepção instrumental ou subentendida sobre as políticas culturais, a segunda aponta para a forma como os grupos sociais se apropriam de seus elementos simbólicos como meio de buscar garantias e melhores posições na vida política, por meio de conteúdos morais para questionar a estigmatização, que visa reforçar, desta forma, uma agenda político-prática de lutas por reconhecimento de novos direitos, econômicos, sociais e políticos (BARBALHO, 2008).

Para a possibilidade de formulação das ciências sociais aplicadas, ambas as abordagens ressaltam, em graus diferenciados, os conflitos do campo cultural e as lutas sociais pela legitimação dos saberes culturais, a formação das estratégias de produção, difusão e consumo de produtos e o embate pelo acesso e significação que cada grupo social dá aos seus bens raros de cultura. Para a construção do planejamento cultural, em especial no âmbito urbano, os dois sentidos devem ser acumuláveis, compreendidos como elementos expressos do campo dos direitos e constitutivos na centralidade das ações, em especial das políticas públicas. Assim sendo, é esta mediação que se impõe quanto à definição básica de uma agenda de intervenções no campo cultural, incorporando os agentes formuladores e o nível decisório dos processos de gestão e planejamento, e os destinatários das políticas.

Nas políticas culturais, portanto, são mediadas e reproduzidas certas partes dos conflitos sociais pelo sentido do mundo e pelas maneiras como os processos de significação são mobilizados no campo autonomizado da cultura, seja na forma como os mercados culturais desenvolvem os bens simbólicos produzidos, seja na pauta prioritária das agendas públicas para a cultura em seus diversos níveis.

Determinar a abrangência das políticas culturais torna-se, desta forma, uma tarefa bastante complexa, justamente por implicar ações de intervenção em diversas esferas da vida societária. Por esforço de síntese, dar-se-á preferência a isolar o sentido da política em dois níveis, respeitando os vínculos iniciais já descritos. Esta primeira reflexão é desdobrada da concepção de Barbalho (2008) sobre o conceito de políticas culturais.

Desta forma, procura-se trabalhar com a ideia de políticas culturais como ações, e elaborações dos discursos sobre estas ações, que têm como objetivo explícito a organização de certas práticas sociais identificadas diretamente com o universo da cultura. Nesta dimensão mais abstrata, combinam-se de forma nuclear duas dimensões fundamentais das relações sociais: o poder e a cultura. Entende-se, assim, que o campo político-cultural é um microcosmo do espaço social onde os agentes sociais disputam, constroem e acionam as regras classificatórias da cultura. 
Procura-se, assim, ampliar o lócus da interação mais óbvia entre cultura e política para um espaço intermediário entre a cultura em seu sentido mais abstrato e a percepção das ações sociais em seu sentido mais concreto. Trata-se de ampliar a interação entre as construções dos modos de vida e ações dos sujeitos na e sobre a realidade urbana e as formas de produção e expressão daquilo que é reconhecido como cultural. A política cultural representaria, assim, um universo de gestão do poder, compreendendo a política como uma dimensão particular da vida social. Trata-se tanto do poder de dizer publicamente o que compreende como cultura, como do poder de definir a melhor forma de seu tratamento, envolvendo quem deve ou não participar de sua organização e o modo mais apropriado de incentivar, de programar, de restringir ou ampliar os espaços de participação, e as razões para a definição das funções espaciais anexas a estas concepções. Todos esses elementos se configuram a partir de relações de força e disputa, "geradas em contexto de reflexividade social institucionalizada e objeto de controvérsia explícita no espaço público" (COSTA, 1997, p. 02).

Como reflexão derivada da instância mais abstrata do fenômeno político-cultural, Barbalho (2009) busca construir um método analítico de caráter bipartite e interdependente. Por um lado, enfatiza o ordenamento dos regimes e formas políticas, por outro, endossa as práticas culturais como construtoras da subjetividade política. Esta distinção se impõe sobre considerações que flutuam entre a busca material da atividade política e os conflitos substanciais do processo político. Para tanto, o autor propõe uma distinção semântica entre policy e politcs e entre "a política" e "o político" a fim de efetivar uma abordagem mais inclusiva do fenômeno político-cultural.

Para efeito de um melhor entendimento, Barbalho sintetiza a política cultural (cultural policy) como "o universo das políticas públicas voltadas para a cultura implementadas por um Governo” e as políticas de cultura (cultural politics) como "as disputas de poder em torno dos valores culturais ou simbólicos que acontecem entre os mais diversos estratos e classes que constituem a sociedade" (BARBALHO, 2009, p.2).

Baseado na distinção inicial proposta por Barbalho, propõe-se estabelecer duas novas tipologias de entendimento do conjunto chamado políticas culturais, não definitivas, mas igualmente complementares. O primeiro desdobramento chamar-se-á políticas culturais cartográfico-institucionais. São as ações de normatização universal e intervenções sobre o campo cultural, mediadas por um conjunto de instituições, fundadas em certa razão tecnocrática e hegemônica, que regulam a vida social. Essas ações definirão, por atitudes deliberadas, conscientes e direcionadas, quais regras gerais e agendas estruturarão a dinâmica organizacional do campo cultural. É neste espaço que se definirão o entendimento e a abrangência do fenômeno cultural, os discursos oficiais que operam a produção legislativa, o escopo de destinatários de políticas, as formas de organização e os meios de financiamento e as competências requeridas para a administração das "coisas públicas de cultura" e para os viabilizadores e produtores de expressões culturais. Quanto à noção de policies, pretende-se não estabelecer um vínculo permanente entre ação política e governo, por vezes restrito ao entendimento das ações do Executivo, mas entre Estado e outros agentes que operam em diferentes níveis de institucionalidade.

O segundo desdobramento será chamado de políticas culturais ético-identitárias. Tratam-se de ações ou perspectivas de ações políticas de grupos sociais que compartilham certo sistema simbólico, coletivo e distintivo. Em geral, essas ações são promovidas quando os interesses destes grupos extravasam ou não se realizam pela agenda cartográfica-institucional. Elas reúnem certo número de lutas sociais, políticas ou culturais, conscientes ou latentes, cuja marca de identificação política, que lhe organiza e lhe dá sentido, é a própria expressão cultural. Quanto à diferenciação da noção de politics, esta se dá pela relativização ao insumo de deliberação consciente presente nas disputas do político, podendo ser interpretadas em razões aparentemente desconexas à orientação sobre a esfera pública - os usos do espaço, por exemplo ${ }^{1}$. Ao assumir como premissa metodológica esta dimensão, pretendo capturar de forma mais extensa as perspectivas dos agentes sociais que operam no campo da cultura, traduzindo demandas mais amplas como o conteúdo pragmático da realização do fenômeno político-cultural.

As duas concepções não são excludentes, ao contrário, expõem que a institucionalidade das práticas políticas responde também à configuração da esfera pública e à materialidade dos processos sociais, políticos e territoriais.

Espera-se verificar, desta forma, que para superar qualquer confronto entre a possibilidade de governança sobre os direitos culturais e o planejamento tecnocrático baseado em uma racionalidade econômico-burocrática, exigem-se modalidades complementares de análise para se perceber o papel das políticas

1 Esta dimensão tem como referência explícita a noção pré-reflexiva do habitus em Bourdieu (2007). 
Artigos

culturais na reprodução social e urbana. Neste sentido, a questão fundamental das políticas culturais está na realização concreta da diversidade cultural, não como um pressuposto exclusivo da institucionalidade, mas como um projeto a se realizar.

\section{Multicultural Planning: a busca de novas representações para o planejamento urbano}

Tentou-se, até aqui, desenhar de forma inicial o quadro conceptivo das políticas culturais trabalhado, segundo sua construção normativa. A discussão retoma a tensão em torno da concepção de pluralismo democrático agora aplicado ao planejamento urbano. Este dado é essencial para apresentar novos modos de operação institucionais baseados na organização do reconhecimento e nas diferenças que não se inscrevem apenas nos alvos, mas na própria intervenção sobre o espaço. Apresenta-se, aqui, uma relevante experiência no campo do planejamento urbano que se afasta da perspectiva econômico-burocrático em favor de um modelo ético-identitário, que rejeita a adoção da racionalidade instrumental em nome do reconhecimento político, no caso, o Multicultural Planning.

A introdução de novas formas de planejamento é fundamental porque direciona outras identidades ao centro de determinação da agenda de redistribuição de bens sociais, reposiciona a tensão entre a particularidade e a universalização do singular e abre espaço para a discussão sobre agenciamento político dos sujeitos a reconhecer. Essa concepção introduz a diferença não como deficiência, mas como recusa de uma igualdade meramente estatutária, aplicando à produção territorial uma gama mais ampla de interpretações acerca dos usos do espaço urbano.

Sandercok formula as bases do Multicultural Planning como uma crítica direta à tecnocracia racionalista. Tendo como tese central as orientações feministas e a teoria do reconhecimento, a autora aborda as implicações para a prática e o ensino do planejamento, admitindo que o conhecimento é uma construção social em disputa. Entre as premissas do Multicultural Planning, está a crítica a uma epistemologia oficial da ciência social, pretendendo construir uma nova base de estudos e outra forma de planejar, mais igualitária e democrática, preservando as especificidades regionais de desenvolvimento.

Mais que a forma, interessa os efeitos do planejamento sobre os sujeitos novo-representados, ampliando a canastra de categorias, outrora invisíveis para a teoria e a prática do planejamento. O caráter invisível das práticas faz supor que a análise do planejamento converge para a estrutura normativa hegemônica ocidental, que corresponde à figura branca, masculina e de classe média-alta (RITZDORF, 1996), deformando a possibilidade de experiências de alteridade. O princípio do Multicultural Planning, portanto, pretende ouvir as vozes esquecidas, superando o risco de ignorar as diferenças.

Ao rejeitar a neutralidade da teoria, os autores do Multicultural Planning ressaltam que as bases do planejamento urbano clássico trazem uma supressão formal das diferenças. Equivale dizer que o debate central deste novo campo se opõe ao caráter pretensamente universal das práticas do planejamento, em nome de uma nova cultura política ético-identitária. As evidências de diferenciação social são trabalhadas ressaltando diferentes leituras sobre a construção da realidade e da disponibilidade de soluções múltiplas a problemas específicos. O substrato desta corrente teórica implica uma mudança nos paradigmas metodológicos de leitura e do léxico predominante da eficiência e da eficácia pela normatividade do conflito social.

A ordem de hierarquização das formas de planejar e do policy cicle muda dos resultados do para o processo ampliado e dialógico do planejamento. O modelo é baseado na flexibilização, com ênfase na negociação e na mediação como ferramentas essenciais na troca política. Supõe-se que esta seja uma das muitas formas que o processo de participação com caráter gerencial das políticas culturais pode assumir.

A contribuição normativa mais interessante destas novas práticas do planejamento vem das teorias feministas, ao compreender o gênero como um aspecto significativo da construção social, cultural, política e econômica da realidade. Centrando sua crítica no policy maker, e revelando que as mudanças no espaço da cidade afetam diferentemente a vida de homens e mulheres, essas análises invertem uma racionalidade funcionalista, que supera valores abstratos como critérios para as decisões do planejamento. Ao chamar a atenção para a análise de gênero para a prática do planejamento, o Multicultural Planning tenta ressaltar que os planejadores assumem e sintetizam valores definidos historicamente como masculinos. 
Ao iniciar uma crítica radical ao funcionalismo essencialista e à concepção vigente do conhecimento e de seu sujeito a partir da denúncia de atributos tidos como masculinos cristalizado nas práticas do planejamento, os autores do Multicultural Planning assumem a perspectiva dos grupos marginalizados e economicamente inferiorizados. Esta composição implica a necessidade de uma teoria e uma prática orientadas para e por múltiplas experiências (SANDERCOK, 1998).

Sem negar o nexo causal entre reivindicações por redistribuição e estrutura político-econômica, os autores ressaltam o acento nas lutas contra as injustiças culturais como uma busca de percepção para uma nova metodologia de planejamento. Ao deslocar a tecnocracia como um dado de neutralidade, realçando a aparência enquanto prática subentendida, esta teoria problematiza o campo do planejamento urbano na superação de padrões de comportamento e consensos cristalizados entre os próprios planejadores.

Ao vincular o debate à perspectiva do reconhecimento, o espaço de representação do planejamento pelo pluralismo democrático tal como definido pelo Multicultural Planning pode propor uma

reavaliação positiva de identidades discriminadas e estereotipadas, bem como dos produtos culturais de grupos marginalizados; valorização da diversidade cultural, ou ainda, a desconstrução e transformação dos padrões societais de representação, interpretação e comunicação para permitir uma maior possibilidade de auto-interpretação para os membros da comunidade política (MATTOS, 2004, p. 146).

A maior contribuição do Multicultural Planning para o campo do planejamento está em sua metodologia de análise. Ao situar o esforço de superação das dominações culturais na prática e ensino do planejamento, os autores diagnosticam uma série de enfrentamentos que impõem "o não-reconhecimento de práticas representacionais, comunicativas e interpretativas de uma cultura, o desrespeito através da esteriotipação de representações públicas nas práticas cotidianas, a criação de mitos de igualdade de participação e expressão" (MAT'TOS, 2004). O critério normativo abstrato escolhido para a realização da análise dos conflitos sociais contemporâneos é a invisibilidade da presença e da fala de certos sujeitos que experimentam a cidade, procurando capturar o maior número possível de expectativas difusas.

O método proposto por Sandercok caminha nesta direção ao tentar capturar outros discursos e propor estudos a partir de experiências vividas na cidade. Esta é uma concepção central para a prática do planejamento das políticas culturais cartográficas, ao privilegiar a experiência de alteridade para a construção das memórias das cidades como um dado a se conhecer.

Revisitando a história do planejamento, percebe-se a existência de uma narrativa oficial que permanece sendo repetida sob duas premissas: i) a história do planejamento modernista; a representação do planejamento como a voz da razão nas sociedades modernas; e ii) são histórias contadas de dentro do Estado, que reforçam a parte da tecnocracia. Mas existem tradições alternativas de planejamento que emergem fora da esfera do Estado e, algumas vezes, em oposição a ele. Cabe ao campo do planejamento urbano reconhecer que a fixação de sua prática opera na seleção de algumas vozes e no silenciamento de outras:

na construção de sua história, a profissão do planejamento está sempre envolvida em moldar a compreensão de seus membros sobre lutas e triunfos do passado e, simultaneamente, criar uma cultura profissional contemporânea em torno dessas memórias, essas histórias. Ao escolher contar algumas histórias em vez de outras, uma identidade profissional é moldada, investida de significado, e depois defendida. Mas quais são os apagamentos e exclusões implícitos no processo de forjar uma identidade profissional? (SANDERCOK, 1998, p. 1, tradução nossa)

Afirmando que o planejamento é uma história encenada oficial que legitima a figura do planejador, não do processo do planejamento, Sandercok defende que esta história oficial

retrata o planejamento como uma atividade heroica, muitas vezes sem nenhuma falha fatal, sempre do lado dos anjos, bem como retrata os que se opõem a ele como irracionais, reacionários ou simplesmente gananciosos. O que isso deixa de fora são os vieses de gênero, classe, raça e cultura da prática do planejamento; as maneiras como os planejadores têm servido como agente de controle social que regula (certos) corpos (marcados) no espaço; as muitas histórias de práticas de resistência, de planejamento feito a partir da 'base' por grupos excluídos, em oposição ao modo de planejamento dirigido pelo Estado que sempre lhes prejudicou (SANDERCOK, 2005, p. 305). 
Artigos

O papel do planejador é visto como uma atividade especializada de administração dos poderes de fala que iguala planejamento e progresso sobre a cidade:

Supõe-se que nós sabemos e concordamos sobre o que o planejamento consiste e o que é e não é um planejador. Supõe-se
que planejar é uma "coisa boa" - uma prática progressista - e que seus oponentes são reacionários, irracionais, ou simples-
mente gananciosos. Supõe-se que os planejadores sabem ou pode adivinhar qual o “interesse público" e que possuem uma
certa experiência que deveria prevalecer (na sociedade racional) sobre a política (SANDERCOK, 1998, p. 3, tradução nossa)

Portanto, para conhecer a cidade em sua ampla dimensão e melhor planejá-la, seria necessário conhecer as histórias nas cabeças dos sujeitos partícipes, interpretá-las e dar um sentido a elas. A aproximação com a política do reconhecimento é expressa pela importância da narração das histórias e as múltiplas possibilidades de enfrentamento da experiência da cidade pelas narrativas invisibilizadas. Esta é uma aposta em uma historiografia subversiva que pode oferecer a cidade como práticas múltiplas. As histórias do planejamento insurgente (insurgent planning histories) desafiam as definições sobre o que constitui o planejamento urbano.

Os planejadores teriam a função de story-tellers, reescrevendo a história urbana e confrontando a prática do planejamento ao poder de representar a cidade por vozes que operam em espaços diferentes dos da tecnocracia ${ }^{2}$. Esta, enquanto um saber instituído, teria por norma a seleção de certas histórias que estruturam o poder e a legitimidade do Estado e, como substrato lógico, o constrangimento de outras vozes.

O uso das histórias serviria como um terreno de experimentação e representação do espaço, da vida e das linguagens da cidade. Sandercok relembra que a 'história oficial' do planejamento tem sido contada por planejadores. Rompendo com a tradição de neutralidade formal do planejamento, torna outras práticas de planejar legíveis e assim constituindo a totalidade da realidade urbana:

estaremos desafiando a exatidão da história oficial e explorando sua dinâmica de compreensão - político-econômico, social, psicológica e cultural - e as relações de poder implícitas nela. Ao apresentar histórias insurgentes se deseja ir além do paradigma modernista de planejamento, para apresentar alternativas a ele, como formas de compreender tanto o passado como imaginar um futuro diferente para o planejamento (SANDERCOK, 1998, p., 2, tradução nossa).

A escolha do tratamento do Multicultural Planning como campo crítico referente ao planejamento cultural não o isenta de limitações. A crítica fundamental pode ser construída sob dois níveis. O primeiro trata de recuperar as convenções sob a ótica nada simples da articulação entre o reconhecimento dos sujeitos sociais ativos e a redistribuição dos bens sociais raros. A questão em si reside na dificuldade de se formular a agenda de direitos diferenciados, ora de distribuição, ora de reconhecimento.

Embora o tratamento dado pelo campo do Multicultural Planning não trate diretamente da questão, internamente esta tensão está presente, sem que seja resolvida. Ao acentuar as formas de planejar sob o espaço de identificação e positivação das diferenças - diga-se, uma contribuição sem precedentes à teoria do planejamento, é possível correr o risco de ignorar a centralidade da exploração capitalista ou de tratá-la como uma identidade a mais. A incorporação léxica neoliberal do progresso à reprodução das cidades não nega, necessariamente, o sentido da multiplicidade de identidades, mas se alimenta dele retoricamente como promoção das mudanças no tecido urbano e nas escolhas de destinação dos fundos públicos (HARVEY, 1996).

O segundo nível sob o qual a crítica é construída é a referência epistemológica do campo e do emprego acrítico do reconhecimento que deve ser questionada. Ao limitar o uso de unidades-síntese como apoio normativo, o Multicultural Planning pode criar abstrações metodológicas que generalizam situações-limite como referências espaciais previamente positivadas a sua concepção de multiculturalismo. Este multiculturalismo, que, via de regra, é polissêmico e tenso, pode tornar-se apenas um meio instrumental de experimentação múltipla da cidade, minimizando o debate das formas institucionais de poder como núcleo das situações de subalternização de classe (poder de polícia, limite do acesso aos bens raros, entre outros) e identidade (formas jurídicas e institucionais de normatização das relações sociais). Este movimento pode secundarizar o aspecto da luta de classes não apenas na reprodução social, mas na formação e na prática do planejamento urbano e das políticas culturais. Uma unidade-síntese fraca ou limitada corre o risco de ser apenas destinada a situações esporádicas, sem efetivar mudanças na esfera institucional de promoção do planejamento.

2 "Para os historiadores, a luta de memórias particulares contra omissões ou supressões particulares também envolve o poder" (Sandercok, 1998, p. 1, tradução nossa). 
Como método, a referência a múltiplos aspectos de centralidade das narrativas pode convergir e situar elaborações transclassistas muito interessantes para a experiência da alteridade e do planejamento. Mas nem todos os indivíduos são dotados dos mesmos instrumentos de enunciação (marcos da própria dimensão da diferença e alteridade), promovendo narrativas que também podem ser antitéticas e inacomodáveis à esfera do planejamento, tal como formulado pelos multiculturalistas. Desta forma, a narrativa positivada ex-ante pode se tornar ainda uma convenção para o aprimoramento de certos instrumentos de manutenção da hegemonia. Para que se seja uma ferramenta eficaz para o planejamento, a metodologia da historiografia insurgente precisa compreender também uma necessidade continuada de tradução das histórias, que esteja atenta às condições de produção - territorial, social, cultural e política - das narrativas. Neste sentido, deveria deslocar-se o caráter episódico de reivindicações e casuístico das representações, avançando sobre a análise ampla do agenciamento político de quem historiciza a prática cotidiana nas cidades.

No Multicultural Planning, é corrente a referência às narrações de histórias de resistência, como um choque à versão oficial do planejamento. Não há dúvidas de que este questionamento de recusa da historiografia atual promove o debate sobre a formação e a prática do planejamento, embora seu escopo de análise limite a esfera do Estado a um polo dicotômico da sociedade civil. Ao não investir em uma dimensão mais profunda da relação Estado/sociedade civil e do caráter substantivo da democracia, as formas de representação institucionais parecem inalienáveis às mudanças externas. O sentido da identidade cultural no Multicultural Planning parece avançar muito pouco à reconfiguração do político e de seu sistema de regulações legais.

O investimento na crítica ao ofício do planejamento multicultural encontra no policy maker seu objeto por excelência. Este entendimento tenta capturar um movimento geral das formas de construção das profissões, embora ignore o caráter histórico de relação íntima com a produção capitalista das cidades e a disputa pela hegemonia. Nesse sentido, o Multicultural Planning não desloca por completo o papel do planejador e o espaço do ofício do planejamento na organização, apenas tenta lhe dar outra função, cuja demanda depende, em larga medida, de seus compromissos individuais.

\section{Outras problematizações}

Mesmo com todas as possibilidades de críticas, o Multicultural Planning pode tornar-se uma ferramenta essencial para a ampliação dos repertórios de formas alternativas de autorrepresentação social para a esfera pública, questionadoras das estruturas de poder e organizadoras dos interesses dos grupos minoritários. Mas para fazê-lo, é preciso reivindicar uma concepção de políticas culturais que acentue sua dinâmica interna conflitiva, não reduzindo seu escopo de atuação ao caráter pragmático da institucionalidade, seja no lugar atribuído à memória social, às diferentes imagéticas produzidas ou interpretadas pelos grupos sociais, ou na viabilização dos meios extremamente especializados de produção da cultura.

Abdicar da identificação das tensões internas do campo normativo das políticas culturais poderia conduzir o tratamento da diversidade cultural a certo instrumentalismo. Nesse sentido, a metodologia de análise do Multicultural Planning pode significar um avanço nas condições de interlocução ou truncamento entre as esferas cartográfico-institucionais e ético-identitárias nas políticas culturais, em especial por tratar da experiência urbana sob um plano multidimensional. Isso pode ocorrer na medida em que se faz possível cooperar a vocalização dos agentes sociais identificados com a dimensão ético-identitária sem subtração das dimensões estruturais da relação entre o Estado, a cultura e o território.

Contudo, para fazê-lo em mediações mais intensas, seria necessário introduzir modalidades metodológicas complementares e um conjunto coerente de técnicas de pesquisa. A primeira e mais evidente é uma radical análise sobre o discurso e de sua atividade produtiva e dialógica de sentido das histórias (PÊCHEUX, 1990).

A segunda faz-se em uma melhor condução das relações entre território, grupos sociais e estado. Neste sentido, a descrição de Lefèbvre (1999) sobre as oposições isotopia e heterotopia pode apresentar-se como uma opção. O autor descreve as tensões entre os espaços da diferença traduzidas nas práticas sociais (heterotopias) e as imbricações entre interesses capitalistas e mecanismos de regulação espacial estatais (isotopia). Como tal, as dimensões territoriais são amplamente apropriadas de forma espontânea pela diferença, na mesma medida em que são reclamadas para a acumulação capitalista. Quando se mostram alinhadas com este processo, precisam construir noções instrumentais da diversidade cultural, rebaixando o campo político-cultural em relação à qualificação do espaço. 
Artigos

Desta forma, quando aplicada à dimensão territorial empírica, as histórias insurgentes tratadas como fontes para o planejamento multicultural podem ser traduzidas tanto em um meio concreto para opor-se à diluição de experiências urbanas, quanto em formas fundamentais para compor uma agenda ampla e progressiva das políticas culturais produzidas nas cidades.

Permitirá às cartografias de políticas culturais, tendo o Estado como seu operativo preferencial, conhecer dimensões morais traduzidas em ações e perspectivas de ações. Como tal, opta-se por poder minimizar possibilidades de negações de direitos fundamentais aos grupos ora reconhecidos como minoritários.

\section{Bibliografia}

BARBALHO, Alexandre. O papel da politica e da cultura nas cidades contemporâneas. In: Políticas Culturais em Revista, 2 (2), p. 1-3, 2009.

Textos Nômades: Política, Cultura e Mídia. Fortaleza: Banco do Nordeste do Brasil, 2008.

BOURDIEU, Pierre. A Distinção: crítica social do julgamento. Porto Alegre: Zouk, 2007.

CANCLINI, Néstor Garcia. Culturas Hibridas: estratégias para entrar e sair da modernidade. São Paulo: Edusp, 2000.

CARRACEDO, José Rubio. Pluralismo, multiculturalismo y cidadanía compleja. In: O’FARRELL, Pablo Badillo. Pluralismo, tolerancia, multiculturalismo: reflexiones para un mundo plural. Andalucía: Ediciones Askal, 2003.

CLOSA, C. Negotiating the Past: Claims for Recognition and Policies of Memory in the EU. Instituto de Políticas y Bienes Públicos(IPP), CCHS-CSIC, Working Paper, Número 8, 2010.

COSTA, António Firmino da: Políticas culturais: conceitos e perspectivas. Obs, n.o 2. Lisboa: Observatório das Actividades Culturais, 1997.

FRASER, Nancy. A justiça social na globalização: Redistribuição, reconhecimento e participação. Revista Crítica de Ciências Sociais, 63, Outubro 2002.

HARVEY, David. A justiça social e a cidade. São Paulo: Hucitec, 1980.

. Condição Pós-Moderna: uma pesquisa sobre as origens da mudança cultural. São Paulo: Loyola, 1996. A produção capitalista do Espaço. São Paulo: Annablume, 2006.

HONNETH, Axel. Luta por reconhecimento: A gramática moral dos conflitos sociais. Trad. Luiz Repa. São Paulo: Ed. 34, 2003.

LEFÈBVRE, Henri. A revolução urbana. Belo Horizonte: UFMG, 1999.

MATTOS, Patrícia. O reconhecimento, entre a justiça e a identidade. Lua Nova, São Paulo, no. 63, 2004.

PÊCHEUX. Análise do Discurso: três épocas. In: GADET, F e HAK, T (orgs). Por uma análise automática do discurso: uma introdução à obra de Pêcheux. Campinas: UNICAMP, 1990.

RITZDORF, Marscha. Feminist thoughts on the theory and practice of planning. In: Campbell, Scott; Fainstein, Susan. Readings in planning theory. Malden/Mass, Blackwell Publishers, 1996, pp. 445-450.

SANDERCOCK, Leonie. Framing insurgent historiographies for planning. In: SANDERCOCK, Leonie. Making the invisibile visible: a multicultural planning history. Berkeley, University of Califórnia Press, 1998, pp. 1-33.

SIMMEL, Georg. A metrópole a vida mental. In: VELHO, Gilberto (org.). O fenômeno urbano. Rio de Janeiro: Zahar , 1976.

WALSH, Catherine. Interculturalidad, Estado, Sociedad: Luchas (de)coloniales de nuestra época. Universidad Andina Simón Bolívar / Ediciones Abya-Yala: Quito, 2009.

WIRTH, Louis. O urbanismo como modo de vida. In: VELHO, Gilberto (org.). O fenômeno urbano. Rio de Janeiro: Zahar, 1976. 